\title{
Foreword to Symposium on Hypertension, Steroid and \\ Mineral Metabolism
}

The affection and admiration we hold for Dr. Bartter is beautifully expressed by Dr. Grant W.Liddle in the preceding pages. In the subsequent pages we seek to update and expand on selected aspects of Dr. Bartter's research interests. The 16 articles to follow are divided into two sections: (1) hypertension and (2) steroid and mineral metabolism.

All the contributors are past or present members of the National Institutes of Health, especially in the Section on Steroid and Mineral Metabolism, Hypertension-Endocrine Branch established by Dr. Bartter over the past quarter century. The idea for this small collection of essays came about during the early part of 1978 when it dawned on those of us still working in the Section that the wonderful years together here may have to come to a close with his retirement from the NIH. Only a select few will have the good fortune to continue daily contact with him in San Antonio; although all of us would hope to continue our collaboration when he establishes the research unit at the VA Hospital and the University of Texas, San Antonio. This Symposium is therefore an effort to catch a glimpse of the achievements of this remarkable and generous man through the eyes of the current and past members of his 'alumni'.

The leading article for the section on hypertension is by Dr. Ivor H. Mills who, like Dr. Liddle, was one of the first trainees to serve with Dr. Bartter and with whom Dr. Bartter took his own sabbatical some years later. His article reviews the kallikrein, kininogen and kinin system and its relationship to blood pressure control. The next five articles are contributed by current members of Dr. Bar tier's group at the NIH and survey the control of renin and aldosterone secretion, and the chronobiologic aspects of hypertension. To conclude the first section of this Symposium, Dr. Bryan and Dr. Brouhard of Texas and Dr. Biglieri of California present brief but definitive papers dealing with the diagnosis and treatment of certain types of hypertension in children and in adults.

Dr. John R.Gill, jr., begins the second section of this Symposium by reviewing the neurogenic control of renal sodium reabsorption, an area of interest to which he has made several important contributions. The next article is

by Dr. Gann who, like Dr. Gill, was also an early member of Dr. Bartter's group. He offers new insight into the mechanism of increased cortisol secretion secondary to hemorrhage. Dr.

Newsome, who also holds the distinction of being one of the several surgeons with research training under Dr. Bartter, enjoys an abiding interest in steroid and mineral metabolism. He reviews the SIADH syndrome and various clinical disorders of vasopressin metabolism.

Dr. Bartter'?, interest in renal endocrine disorders in children is reflected in the large number of pediatricians who have been attracted to seek training with him. Dr. Simopoulos, who delineated the growth and development of children with the Bartter's syndrome in the original studies, reevaluates and updates such data in the light of recent advances. The next contributor is Dr. Broadus, who enlarges upon some of the definitive work he did on cyclic AMP during his years 
at Dr. Bartter's laboratory and incorporates some of his subsequent thoughts on the subject in the article on nephrogenic cyclic AMP as a parathyroid function test.

Dr. Bartter's interests in calcium and acid-base disorders (probably stimulated early when he was himself a trainee under Dr. Fuller Albright) are represented in the final three articles: on kidney stones (Dr. Pak), hyper-calcemia and hypocalcemia (Dr. Bell) and renal tubular acidosis.

As in most major branches of learning, it would seem inevitable for an old master (Fuller Albright) to open a new field of study, which was then developed to tremendous heights by a new master (Frederic Bartter), who subsequently fostered a whole generation of disciples. A small glimpse of the scope of this paternal influence is presented here in this Symposium. It is the great fortune for so many of us to have worked under such a person and to look forward to many more years of interactions with this great teacher. To Frederic C. Bartter, to whom we owe so much and for 'the debt we can never repay', may we wish him many more 'works of noble note... yet to come'.

James C. M. Chan, MD, Medical College of Virginia, Box 822, MCV Station, Richmond, VA 23298 (USA) 